\title{
CENÁRIOS PROSPECTIVOS COM BASE NOS PROJETOS DE LEI PARA ACESSIBILIDADE NA WEB NO BRASIL
}

\author{
PROSPECTIVE SCENARIOS BASED ON LAW PROJECTS FOR WEB ACCESSIBILITY IN \\ BRAZIL
}
ESCENARIOS PROSPECTIVOS BASADOS EN PROYECTOS DE LEY PARA LA
ACCESIBILIDAD DE LA WEB EN BRASIL

${ }^{1}$ Wagner Junqueira de Araújo

1Ítalo José Bastos Guimarães

${ }^{1}$ Marckson Roberto Ferreira de Sousa

${ }^{1}$ Universidade Federal da Paraíba

Correspondência

${ }^{1}$ Wagner Junqueira de Araújo ${ }^{(D)}$

Universidade Federal da Paraíba

João Pessoa, PB

E-mail: wagnerjunqueira.araujo@gmail.com

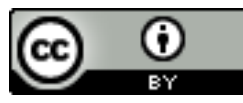

JITA: FJ. Knowledge management

Submetido em: 23/05/2018

Aceito em: 11/07/2018

Publicado em: 27/08/2018 
RESUMO: Aborda a temática da acessibilidade e tem como objetivo elaborar cenários prospectivos para acessibilidade na web com base nos projetos de lei do Senado Federal e da Câmara dos Deputados. Apresenta um levantamento sobre as principais leis sobre acessibilidade que estão em vigor no Brasil. Para tanto, utiliza-se do método de matrizes de impacto cruzado de Gordon. Foi necessário realizar um levantamento sobre os atuais projetos de lei que estão em tramitação para embasar a projeção de cenários. Deste modo, identificou-se quatro projetos de lei que tratam da acessibilidade na web. A partir dos dados elaborados por meio do método de Gordon, foi possível desenvolver três cenários, a saber: a) pessimista - não ocorrência dos eventos previstos gerando o arquivamento ou não aprovação dos projetos em tramitação; b) realista - cenário mais provável é a ocorrência do desenvolvimento de Centros de Inclusão Digital (CID) por meio da aprovação da Lei da Câmara $n^{\circ} 28$, de 2011; c) otimista - além do desenvolvimento do CID é possível que ocorra a implantação de programas de software nas bibliotecas públicas para uso de deficientes visuais, como também a promoção da acessibilidade aos portais públicos na web no médio prazo. Sendo assim, observa-se por meio dos cenários propostos, um panorama sobre o que pode ocorrer em relação aos projetos de lei avaliados.

PAlavraS-ChaVE: Gestão da informação. Gestão do conhecimento. Cenários. Acesso à informação. Legislação

ABSTRACT: This paper addresses the theme of accessibility and aims to develop prospective scenarios for accessibility on the web based on the bills of the Federal Senate and the Chamber of Deputies. It presents a survey about the main accessibility laws that are in force in Brazil. For this, it was used the crossimpact matrix method of Gordon. It was necessary to carry out a survey on the current bills that are in process to support the projection of scenarios. In this way, four bills have been identified about accessibility on the web. Based on the Gordon method, it was possible to develop three scenarios: a) pessimistic - no occurrence of expected events generating the archiving or non-approval of the projects being processed; b) realistic - occurrence of the development of Digital Inclusion Centers (CID) through the approval of Law no.28, of 2011; c) optimistic - in addition to the development of the CID, it is possible to implement software programs in public libraries for the use of the visually impaired, as well as to promote accessibility to public web portals in the medium term. Thus, we can see through the proposed scenarios a panorama of what can happen without future in relation to the bills projects.

KEYWORDS: Information management. Knowledge management. Scenarios. Access to information. Legislation.

RESUMEN: Aborda la temática de la accesibilidad y tiene como objetivo elaborar escenarios prospectivos para accesibilidad en la web con base en los proyectos de ley del Senado Federal y de la Cámara de Diputados. Presenta un levantamiento sobre las principales leyes sobre accesibilidad que están en vigor en Brasil. Para ello, se utiliza el método de matrices de impacto cruzado de Gordon. Fue necesario realizar un levantamiento sobre los actuales proyectos de ley que están en tramitación para basar la proyección de escenarios. De este modo, se identificaron cuatro proyectos de ley que tratan de la accesibilidad en la web. A partir de los datos elaborados por medio del método de Gordon, fue posible desarrollar tres escenarios, a saber: a) pesimista - no ocurrencia de los eventos previstos generando el archivo o no aprobación de los proyectos en tramitación; b) realista escenario más probable es la ocurrencia del desarrollo de Centros de Inclusión Digital (CID) por medio de la aprobación de la Ley de la Cámara $n^{\circ} 28$, de 2011; c) optimista - además del desarrollo del CID es posible que ocurra la implantación de programas de software en las bibliotecas públicas para uso de deficientes visuales, así como la promoción de la accesibilidad a los portales públicos en la web a medio plazo. Siendo así, se observa por medio de los escenarios propuestos, un panorama sobre lo que puede ocurrir en relación a los proyectos de ley evaluados.

PAlABRAS Clave: Gestión de la información. Gestión del conocimiento. Escenarios. Acceso a la información. Legislación. 


\section{INTRODUÇÃ̃o}

Sabe-se que a internet é um ambiente que proporciona interação, troca de conteúdo, experiências e comunicação. Não é novidade a sua importância para a sociedade, especialmente na era pós-digital. O ponto que se discute neste trabalho, é como seria possível proporcionar um ambiente digital acessível para todos os tipos de usuários. Nesse sentido, o artigo aborda a temática da acessibilidade e tem como objetivo elaborar cenários prospectivos sobre o tema acessibilidade na web com base nos projetos de lei do Senado Federal e da Câmara dos Deputados.

Com o foco da Ciência da Informação, essa pesquisa busca integrar a informação estratégica e o estudo prospectivo de cenários para auxiliar na construção de cenários futuros sobre as propostas para a acessibilidade na Web.

No país, segundo levantamento realizado pelo último Censo do IBGE em 2010, por meio da Cartilha do CENSO 2010 - pessoas com deficiência (BRASIL, 2012), cerca de 23,9\% da população brasileira possui alguma deficiência física - visual, auditiva, motora, mental ou intelectual. O número corresponde a mais de 45 milhões de pessoas, em sua maioria residentes em áreas urbanas. Esta parte da população, tem, as mesmas necessidades de comunicação, de acesso a informação, ao comercio eletrônico, e a todos os demais recursos oferecidos pelos meios digitais, como qualquer outro cidadão.

Para Henry (2005), trazer acessibilidade ao meio digital pode beneficiar outras pessoas, além dos usuários deficientes. Isto porque, por meio de ações de acessibilidade, pessoas mais idosas ou com certo grau de dificuldade serão favorecidas. No entanto, empresas e organizações que atuam na Web precisam de alguns elementos motivadores para oferecer meios acessíveis a esta parte da população, tais elementos podem vir por forças do próprio mercado, ou por regulamentações legais.

Para entender como esta perspectiva legal está se organizando, elaborou-se as seguintes questões: quais são os atuais projetos de lei referentes à acessibilidade na web que estão tramitando no Senado Federal e na Câmara dos Deputados? Quais impactos podem ser gerados por meio de eventuais aprovações destes projetos? Que tipo de cenário poderemos projetar para os próximos anos em relação à acessibilidade na web?

Lazzarin (2014) e Guimarães (2016) concordam com o pressuposto de Henry (2005) que tornar um ambiente digital acessível é fundamental para promover a igualdade de oportunidades. O desafio é envolver as partes para atuarem no desenvolvimento das ações, de tal modo que venham a compreender as reais necessidades dos usuários deficientes. Tais ações podem se materializar como propostas de projetos de leis, envolver empresas e instituições interessadas, desenvolver tecnologia e torná-la acessível para estes usuários. 
Sendo assim, um dos "atores" importantes neste processo é o governo federal por meio do seu poder Legislativo.

Considera-se projeto de lei como "o documento legislativo que tem como objetivo iniciar o processo de criação de uma lei ordinária ou de alteração uma lei ordinária existente" (CÂMARA DOS DEPUTADOS, 2018). Além disso, o Senado Federal (2018) define projeto de lei como "um conjunto de normas que deve submeter-se à tramitação num órgão legislativo com o objetivo de efetivar-se através de uma lei”. Logo, para fins de avaliação do presente estudo, foram utilizados os projetos de lei em tramitação no Senado Federal e na Câmara dos Deputados.

\section{LEGISLAÇÃO SOBRE ACESSIBILIDADE}

Para tratar das leis sobre acessibilidade é preciso recorrer ao primeiro marco internacional que originou outras discussões acerca da temática. No dia 10 de dezembro de 1948, ocorreu uma Assembleia Geral das Nações Unidas, onde foi proclamada a Declaração Universal dos Direitos Humanos. A partir desta, a resolução 217 A (III) buscou prover igualdade para todos os povos e nações. São 30 artigos que reconhecem os direitos humanos, de acordo com o documento da ONU (1948) "[...] como o ideal comum a ser atingido por todos os povos e todas as nações".

A partir desta declaração, ocorreu a validação da compreensão de que todos os seres humanos merecem ser tratados de forma igualitária. Desde então, uma das alternativas para buscar este objetivo, além dos aspectos como educação e conscientização das pessoas, é propor leis que proporcionem igualdade de oportunidades.

\subsection{Legislação Internacional}

Sabe-se que a maior parte dos países possui autonomia para elaborar e aprovar as próprias leis. Destaca-se nesta seção, apenas as principais convenções internacionais que trataram sobre acessibilidade, bem como resoluções da ONU e algumas declarações internacionais. $O$ quadro 1 sintetiza as convenções internacionais que trataram da acessibilidade.

Quadro 1. Convenções internacionais sobre acessibilidade

\begin{tabular}{|c|c|l|}
\hline Convenções internacionais & Ano & \multicolumn{1}{|c|}{ Principais pontos } \\
\hline Convenção OIT 111 & 1958 & $\begin{array}{l}\text { Trata da discriminação de salários e critérios de } \\
\text { admissão de trabalhadores portadores de alguma } \\
\text { deficiência. }\end{array}$ \\
\hline Convenção OIT 159 & 1983 & $\begin{array}{l}\text { Refere-se a reabilitação profissional e emprego de } \\
\text { pessoas com deficiência. }\end{array}$ \\
\hline \hline
\end{tabular}




\begin{tabular}{|c|c|l|}
\hline Convenção OIT 168 & 1988 & $\begin{array}{l}\text { Busca promover o emprego e garantir a proteção } \\
\text { contra o desemprego de pessoas com deficiência. }\end{array}$ \\
\hline $\begin{array}{c}\text { Convenção sobre o direito da } \\
\text { criança }\end{array}$ & 1989 & $\begin{array}{l}\text { Trata dos cuidados relativos à criança com } \\
\text { deficiência. }\end{array}$ \\
\hline Convenção da Guatemala & 1999 & $\begin{array}{l}\text { Busca eliminar todas as formas de discriminação } \\
\text { contra pessoas com deficiência. }\end{array}$ \\
\hline $\begin{array}{l}\text { Convenção sobre os Direitos } \\
\text { das Pessoas com Deficiência }\end{array}$ & 2009 & $\begin{array}{l}\text { Visa promover, proteger e assegurar pleno e } \\
\text { equitativo de todos os direitos humanos e liberdades } \\
\text { fundamentais por todas as pessoas com deficiência. }\end{array}$ \\
\hline
\end{tabular}

Fonte: Adaptado de FADERS (2018)

Dentre as convenções apresentadas no Quadro 1, uma das mais importantes foi justamente a convenção sobre Direitos das Pessoas com Deficiência realizada em 2009. Outro marco importante foi a realização da Convenção da Guatemala, onde foram definidas as formas de discriminação em relação aos deficientes. Ambas Convenções foram relevantes para o Brasil, pois se transformaram em Decretos de Lei, detalhados na seção seguinte.

Quadro 2. Resoluções da ONU sobre acessibilidade

\begin{tabular}{|c|c|l|}
\hline Resoluções & Ano & \multicolumn{1}{|c|}{ Principais pontos } \\
\hline Resolução ONU 2.896 & 1971 & $\begin{array}{l}\text { Trata dos direitos à atenção médica e ao tratamento } \\
\text { médico exigidos aos deficientes mentais. }\end{array}$ \\
\hline Resolução ONU 3.447 & 1975 & $\begin{array}{l}\text { Trata sobre a Declaração dos Direitos das Pessoas } \\
\text { Portadoras de Deficiências. }\end{array}$ \\
\hline Resolução ONU 37/52 & 1982 & $\begin{array}{l}\text { Estabelece diretrizes para açães nacionais, } \\
\text { internacionais, pesquisa e controle a avaliação do } \\
\text { Programa de Ação Mundial para Pessoas } \\
\text { Deficientes. }\end{array}$ \\
\hline Resolução ONU 45/91 & 1990 & $\begin{array}{l}\text { Trata da execução do Programa de Ação Mundial } \\
\text { para as Pessoas Deficientes e da Década das Pessoas } \\
\text { com Deficiência das Nações Unidas. }\end{array}$ \\
\hline Resolução ONU 46 & 1991 & $\begin{array}{l}\text { Trata da execução do Programa de Ação Mundial } \\
\text { para as Pessoas Deficientes e da Década das Pessoas } \\
\text { com Deficiência das Nações Unidas. }\end{array}$ \\
\hline Resolução ONU 47/3 & 1992 & $\begin{array}{l}\text { Sessão Plenária Especial sobre Deficiência, da } \\
\text { Assembleia Geral da ONU, adotou o dia 03 de } \\
\text { dezembro como o Dia Internacional das Pessoas com } \\
\text { Deficiência. }\end{array}$ \\
\hline
\end{tabular}

Fonte: Adaptado de FADERS (2018)

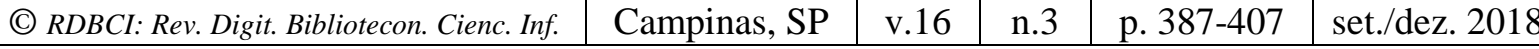


O quadro 2 sintetiza as principais resoluções da ONU desde o ano de 1971 até 1993. Estas resoluções são importantes, pois denotam os primeiros esforços internacionais para inclusão social. Desde as necessidades básicas como saúde, abordada na Resolução ONU 2.896, até equiparação de oportunidades de trabalho para pessoas com deficiência, como descreve a Resolução ONU 48/96.

As discussões internacionais despertaram a necessidade de criação de leis específicas, adaptadas à realidade de cada país. No Brasil, especificamente, começa-se a regulamentação por meio de lei no final da década de 80 .

\subsection{Legislação vigente no Brasil}

$\mathrm{Na}$ legislação brasileira existem normas que abordam as deficiências auditivas, visuais, motoras ou mentais. As ações governamentais brasileiras de políticas de integração e inserção social dos deficientes são baseadas na Lei no 7.853 de 23 de outubro de 1989 (BRASIL, 1989) que regulamenta aspectos importantes ao apoio às pessoas com deficiência, sua integração social e define o papel da Coordenadoria Nacional para Integração da Pessoa Portadora de Deficiência (CORDE) e no Decreto n 3.298 de 20 de dezembro de 1999 que consolida as normas de proteção relacionadas a Política Nacional para Integração da Pessoa Portadora de Deficiência (BRASIL, 1989; BRASIL, 1999).

Antes disso, contudo, a própria Constituição Federal de 1988 trata de questões pontuais acerca da acessibilidade como descreve em seu Artigo 24, XIV que: "Compete à União, aos Estados e ao Distrito Federal legislar concorrentemente sobre: [...] proteção e integração social das pessoas portadoras de deficiência" (BRASIL, 1988, online).

O artigo 55 do Decreto ${ }^{\circ}$ 3.298/99 descreve aspectos relacionados ao levantamento de informações sobre os deficientes e a relevância da realização de pesquisas que beneficiem estes cidadãos. Assim, determina o Decreto nº 3.298 (BRASIL, 1999, online):

\footnotetext{
Capítulo X

Do Sistema Integrado de Informações

Art. 55. Fica instituído, no âmbito da Secretaria de Estado dos Direitos Humanos do Ministério da Justiça, o Sistema Nacional de Informações sobre Deficiência, sob a responsabilidade da CORDE, com a finalidade de criar e manter bases de dados, reunir e difundir informação sobre a situação das pessoas portadoras de deficiência e fomentar a pesquisa e o estudo de todos os aspectos que afetem a vida dessas pessoas.
}

A partir dos anos 2000, com o início da popularização das tecnologias de informação e comunicação (TICs), foi sancionada a Lei $\mathrm{n}^{\mathrm{o}} 10.0$ 98/00 que trata sobre aspectos relacionados à responsabilidade do Poder Público em atuar na eliminação das eventuais barreiras de comunicação e informação. O artigo 17 da Lei n ${ }^{\circ} 10.098$ (Brasil, 2000, online) esclarece: 
Art. 17. O Poder Público promoverá a eliminação de barreiras na comunicação e estabelecerá mecanismos e alternativas técnicas que tornem acessíveis os sistemas de comunicação e sinalização às pessoas portadoras de deficiência sensorial e com dificuldade de comunicação, para garantir-lhes o direito de acesso à informação, à comunicação, ao trabalho, à educação, ao transporte, à cultura, ao esporte e ao lazer.

A partir da responsabilidade assumida pelo governo federal, de assegurar às pessoas com deficiência, o acesso à informação e comunicação, inclusive às tecnologias de informação e comunicação, há um engajamento maior com a finalidade de identificar e eliminar as barreiras de acessibilidade. Dentre as principais ações que podem ser executadas pelo governo federal, destaca-se a atuação em conjunto com o poder legislativo com o objetivo de aprovar leis que garantam a acessibilidade nos ambientes informacionais digitais. No que diz respeito aos websites do poder público, foi sancionado o Decreto $\mathrm{N}^{\mathrm{o}} 5.296$ (BRASIL, 2004, online) que retrata sobre:

\section{CAPÍTULO VI \\ DO ACESSO À INFORMAÇÃO E À COMUNICAÇÃO}

Art. 47. No prazo de até doze meses a contar da data de publicação deste Decreto, será obrigatória a acessibilidade nos portais e sítios eletrônicos da administração pública na rede mundial de computadores (internet), para o uso das pessoas portadoras de deficiência visual, garantindo-lhes o pleno acesso às informações disponíveis.

Em dezembro de 2006, foi realizada a Convenção sobre os Direitos das Pessoas com Deficiência adotada pela ONU. Dois anos após o evento, o Congresso Nacional aprovou o texto da Convenção e de seu protocolo facultativo em 2008 - Decreto Legislativo $\mathrm{n}^{\mathbf{0}} 186$, considerado um marco para a garantia dos direitos e equidades sociais para os deficientes. $\mathrm{O}$ propósito da Convenção, de acordo com a Legislação Brasileira de Portadores de deficiência (BRASIL, 2009, online) foi "promover, proteger e assegurar o exercício pleno e equitativo de todos os direitos humanos e liberdades fundamentais por todas as pessoas com deficiência e promover o respeito pela sua dignidade inerente". Em agosto de 2009, foi assinado o decreto n 6949/09, promulgando a Convenção Internacional sobre os Direitos das Pessoas com Deficiência no Brasil (CDPD).

O texto aprovado pela CDPD aprovou 50 artigos relacionados aos temas mais preocupantes e que apresentam maiores dificuldades aos deficientes, como educação, saúde, recreação, lazer, esporte, trabalho, emprego, habitação, tratados de cooperações internacionais, entre outros. Em relação à acessibilidade, o artigo 9 da CDPD (BRASIL, 2009, online) destaca:

[...] os Estados-Partes tomarão as medidas apropriadas para assegurar às pessoas com deficiência o acesso, em igualdade de oportunidades com as demais pessoas, ao meio físico, ao transporte, à informação e comunicação, inclusive aos sistemas e tecnologias da informação e comunicação, bem como a outros serviços e instalações abertos ao público ou de uso público, tanto na zona urbana como na rural. Essas medidas, que incluirão a identificação e a eliminação de obstáculos e barreiras à acessibilidade, serão aplicadas, entre outros, a: 
a. Edifícios, rodovias, meios de transporte e outras instalações internas e externas, inclusive escolas, residências, instalações médicas e local de trabalho;

b. Informações, comunicações e outros serviços, inclusive serviços eletrônicos e serviços de emergência.

De acordo com Cousin (2010), os direitos estabelecidos por lei são estendidos à população independentemente se possuem ou não alguma deficiência, pois contribuem para a evolução da internet e promoção de igualdade de oportunidades.

Recentemente, em 06 de julho de 2015, foi sancionada a Lei Brasileira de Inclusão da Pessoa com Deficiência - LBI - Lei no 13.146 (BRASIL, 2015, online). Ela contém 127 artigos que são divididos em três capítulos. A lei foi criada para "assegurar e a promover, em condições de igualdade, o exercício dos direitos e das liberdades fundamentais por pessoa com deficiência, visando à sua inclusão social e cidadania". O capítulo II foi destinado a tratar do acesso à informação e à comunicação. O artigo 63 da LBI (BRASIL, 2015, online), relata:

É obrigatória a acessibilidade nos sítios da internet mantidos por empresas com sede ou representação comercial no País ou por órgãos de governo, para uso da pessoa com deficiência, garantindo-lhe acesso às informações disponíveis, conforme as melhores práticas e diretrizes de acessibilidade adotadas internacionalmente.

Para Guimarães (2016) é dever do poder legislativo a elaboração de projetos de lei e decretos que regulamentem padrões internacionais de acessibilidade. O propósito seria promover o acesso aos websites brasileiros com a finalidade de eliminar as barreiras informacionais que impossibilitam a interação dos usuários.

A partir do levantamento realizado sobre a legislação vigente no Brasil é possível compreender que o país avança, ainda que em passos lentos, para propor ambientes informacionais digitais acessíveis. De todo modo, as leis precisam ser realmente aplicadas, isto porque a legislação vigente permanece omissa em pontos relevantes e por este motivo pode não gerar os benefícios esperados ou até mesmo propostos por lei.

\section{CENÁRIOS PROSPECTIVOS E O USO DAS MATRIZES DE IMPACTOS CRUZADOS}

A prospecção de cenários é comumente utilizada por empresas. As organizações buscam compreender as complexas variáveis que as influenciam e a velocidade de mudanças que impactam suas ações. Para Moritz e Pereira (2005), as organizações estão enfrentando diversas ameaças, principalmente relacionadas às inovações tecnológicas e necessitam de cenários prospectivos para identificar as forças dinâmicas que prevalecerão nos próximos anos. Na Ciência da informação, Santos (2017, p. 18) apresenta um resumo dos trabalhos que utilizaram as metodologias de cenários prospectivos publicados no Brasil. A autora indica que tais trabalhos estão relacionados principalmente com a gestão da informação estratégica. 
Não obstante, a utilização de cenários prospectivos pode ser aplicada à compreensão da realidade sobre acessibilidade na web no Brasil. Observar os projetos de lei que estão em tramitação e criar cenários pode ser útil para o desdobramento das ações e estratégias adotadas por todos envolvidos na inclusão social e digital de pessoas com deficiência.

Desde a fundação da web, uma das principais intenções sempre foi torná-la universal, ou seja, permitir que a internet possa ser utilizada por qualquer pessoa, independente das barreiras impostas (ALEXANDER, 2003). Neste sentindo, institutos e órgãos se esforçam para elaborar ações que proporcionem um ambiente digital acessível.

O foco do artigo não é se debruçar diante das definições sobre acessibilidade na web, mas compreender como a elaboração de cenários pode auxiliar no entendimento sobre quais leis podem gerar impactos positivos ou negativos no dia-a-dia do cidadão deficiente no Brasil.

Godet e Durance (2011, p. 28) afirmam que um cenário é "um conjunto formado pela descrição de uma situação futura e pela cadeia de acontecimentos que permitem passar da situação de origem à situação futura". Para os autores, não se deve confundir elaboração de cenários como um jogo de hipóteses, é necessário adotar as seguintes condições, em simultâneo: a pertinência, a coerência, a verossimilhança, a importância e a transparência.

Santos et al. (2004) relatam que podem ser esperados os seguintes benefícios dos exercícios de prospecção de cenários associados à ciência, tecnologia e inovação: (a) promoção de canais e linguagens comuns para a circulação de informação e conhecimento de caráter estratégico para a inovação; (b) mais inteligência antecipatória inserida no processo de tomada de decisão em ciência, tecnologia e inovação; (c) incorporação crescente de visões de futuro no pensamento dos atores sociais envolvidos no processo de tomada de decisão e de criação de redes; (d) apoio a decisões relativas ao estabelecimento de prioridades para P\&D, gestão dos riscos das inovações tecnológicas, melhoria da competitividade tecnológica de produtos, processos e serviços. Com base nesta descrição, o Quadro 3 apresenta os principais benefícios da prospecção de cenários aplicados à acessibilidade na web.

Quadro 3. Principais benefícios da prospecção de cenários para acessibilidade na web no Brasil

\begin{tabular}{|l|l|l|}
\hline Inclusão Social e digital: & $\begin{array}{l}\text { Promover, elaborar ou desenvolver políticas públicas para } \\
\text { proporcionar inclusão social e digital no Brasil. }\end{array}$ \\
\hline Usuários: & $\begin{array}{l}\text { Compreender as futuras necessidades dos usuários deficientes em } \\
\text { relação ao uso da web. }\end{array}$ \\
\hline Organizações/Empresas: & $\begin{array}{l}\text { Apoiar as decisões relativas ao estabelecimento de novos negócios } \\
\text { ou empreendimentos que atendam às necessidades de pessoas com } \\
\text { deficiência na web. }\end{array}$ \\
\hline Instituições de fomento: & \multicolumn{5}{|l|}{ Auxiliar instituições engajadas no desenvolvimento de ações para } \\
\hline
\end{tabular}




\begin{tabular}{|l|l|}
\hline & minimizar as barreiras de acessibilidade na web. \\
\hline Sociedade: & $\begin{array}{l}\text { Compreender as visões de futuro que impactam o pensamento dos } \\
\text { atores sociais envolvidos. }\end{array}$ \\
\hline
\end{tabular}

Fonte: Elaborado pelos autores (2018)

A projeção de cenários, como explicam Lira, Araújo e Duarte (2017), pode ser elaborada com base em diferentes métodos e abordagens. Os autores destacam o modelo de cinco forças de Porter, modelo de análise de cenários proposto por Lee et al. (2015), o método delphi, e, por fim, o método proposto por Godet (2006).

Além dos métodos mencionados, existe a Análise Matricial de Impactos Cruzados para projeção de cenários. Este método foi elaborado em 1966 por Theodore Gordon e Olaf Helmer. Baseia-se no conceito de que a ocorrência de um determinado fenômeno, evento ou ação pode afetar a probabilidade de ocorrência de um conjunto de outros fenômenos, eventos, ou ações. Para isso, recomenda-se a definição das interações (principais variáveis) e suas devidas intensidades (possibilidades de ocorrência). A partir de então, utiliza-se um software para auxiliar na análise das possíveis combinações e as frequências de ocorrência, para que possam ser gerados os cenários (KAMIMURA, 1994).

Santos (2011) relata que este método inter-relaciona todas as tendências a uma questão de estudo. Essa inter-relação estabelecida pode ser mensurada por meio de um modelo matricial através da atribuição de valores numéricos. Gordon (1999) detalha as etapas do método proposto, conforme apresenta a Quadro 4:

Quadro 4. Etapas do método de impacto cruzado de Gordon (1999)

\begin{tabular}{|l|l|}
\hline Etapas: & Descrição: \\
\hline (1) Definir os eventos do estudo & $\begin{array}{l}\text { Etapa essencial para alcançar o resultado esperado. Recomenda- } \\
\text { se definir apenas os eventos essenciais e mais relevantes (entre } \\
10 \text { e } 40 \text { eventos). A análise de impacto cruzado se simplifica } \\
\text { quando os eventos são independentes. }\end{array}$ \\
\hline $\begin{array}{l}\text { (2) Calcular a probabilidade } \\
\text { inicial de cada evento }\end{array}$ & $\begin{array}{l}\text { De modo inicial, a probabilidade de cada evento é especificada } \\
\text { de forma separada, assumindo que os outros eventos não } \\
\text { ocorram. A análise de impacto cruzado é usada para ajustar as } \\
\text { probabilidades iniciais com as influências de outros eventos. }\end{array}$ \\
\hline $\begin{array}{l}\text { (3) Estimar as probabilidades } \\
\text { condicionais }\end{array}$ & $\begin{array}{l}\text { Os impactos são estimados com base no seguinte } \\
\text { questionamento: se um evento "x" acontece, qual a nova } \\
\text { probabilidade de ocorrência do evento "y"? Pode-se utilizar um } \\
\text { software para calcular a estimação das probabilidades e a } \\
\text { elaboração da matriz de impacto cruzado. }\end{array}$ \\
\hline
\end{tabular}

Fonte: Adaptado de Gordon (1999) 
Wright, Silva e Spers (2010) comentam que para elaborar uma projeção de cenários é preciso que o cenarista leve em consideração as forças que atuam sobre seu objeto de estudo. Desta forma, é fundamental compreender as forças restritivas e propulsoras que atuam sobre as variáveis identificadas, além de considerar os limites naturais e sociais que podem evoluir no horizonte de tempo em análise. Obviamente, o método de matriz de impacto cruzado, assim como os demais, possui vantagens e desvantagens. A metodologia concentra-se, como afirma Gordon (1999), na relação de causalidade e dependendo da coleta de dados pode ser bastante exaustiva devido à extensão do número de eventos. O método de matriz de impacto cruzado foi escolhido para este trabalho pois possui os instrumentos necessários para atender o objetivo proposto e foi o que mais se adequou a fonte de informações utilizadas.

\section{PROCEDIMENTOS METOdOLÓgicos}

A pesquisa foi de abordagem qualitativa e do tipo descritiva. Para Minayo (2009), uma pesquisa qualitativa busca responder aspectos muito particulares de uma determinada realidade. Neste sentido, o presente estudo buscou aprofundar-se nos projetos de lei sobre acessibilidade na web que estão em tramitação no poder legislativo. Conforme relatam Neves e Domingues (2007), em pesquisas qualitativas, o pesquisador aproxima-se do seu objeto de estudo, permitindo um melhor detalhamento dos seus resultados. Se caracteriza como pesquisa descritiva, pois buscou-se relatar os três cenários possíveis (pessimista, realista e otimista), descrevendo suas possibilidades de ocorrência. Gil (2008, p. 28) afirma que "pesquisas deste tipo tem objetivo primordial a descrição das características de determinada população ou fenômeno ou estabelecimento de relações entre variáveis".

A elaboração dos cenários prospectivos para acessibilidade na web no Brasil foi baseada no modelo de impacto cruzado de Gordon (1999). Para observar as etapas propostas pelo método, foi necessário realizar um levantamento dos atuais projetos de lei que estão em tramitação no Senado Federal e na Câmara dos Deputados.

Deste modo, realizou-se uma coleta com uso de filtros de pesquisa. Os dados foram coletados no dia 23 de janeiro de 2018, por meio do portal do Senado Federal (http://www25.senado.leg.br/web/atividade/materias), através da busca avançada. Foram utilizados os filtros de pesquisa "em tramitação", e o uso da palavra-chave "acessibilidade". Desta forma, surgiram 17 projetos de lei em tramitação no Senado Federal e 5 projetos de Lei em tramitação na Câmara, conforme ilustra o Quadro 5.

Quadro 5. Projetos de Lei sobre acessibilidade (em tramitação)

\begin{tabular}{|c|c|c|}
\hline Projetos de Lei & $\begin{array}{c}\text { Projetos de Lei do Senado } \\
\text { (PLS) }\end{array}$ & $\begin{array}{c}\text { Projetos de Lei da Câmara } \\
\text { (PLC) }\end{array}$ \\
\hline $\begin{array}{l}\text { Tratam da Acessibilidade } \\
\text { como um todo (transporte }\end{array}$ & $\begin{array}{l}15 \text { projetos de lei em } \\
\text { tramitação }\end{array}$ & 3 projetos de lei em tramitação \\
\hline
\end{tabular}




\begin{tabular}{|c|c|c|}
\hline público, estacionamentos, etc) & \\
\hline Acessibilidade na web & $\begin{array}{c}2 \text { projetos de lei em } \\
\text { tramitação }\end{array}$ & 2 projetos de lei em tramitação \\
\hline
\end{tabular}

Fonte: Elaborado pelos autores (2018), baseado em informações do portal do Senado Federal

A partir do resultado, foi realizada uma verificação, por meio da leitura de cada projeto com a finalidade de identificar os que estariam relacionados apenas com acessibilidade na web. Sendo assim, foram encontrados 4 projetos de lei em tramitação no Senado e na Câmara, dois em cada órgão Legislativo. O Quadro 6 descreve as principais informações sobre os PLS e PLC.

Quadro 6. Detalhamento dos projetos de Lei sobre acessibilidade na web

\begin{tabular}{|c|c|c|c|c|}
\hline & Protocolado & Autoria & Ementa & Explicação da ementa \\
\hline $\begin{array}{c}\text { Projeto de } \\
\text { Lei do } \\
\text { Senado no } \\
138 \text {, de } 2014\end{array}$ & $23 / 04 / 2014$ & $\begin{array}{c}\text { Senador Ciro } \\
\text { Nogueira } \\
(\mathrm{PP} / \mathrm{PI})\end{array}$ & $\begin{array}{l}\text { Dispõe sobre a } \\
\text { implantação } \\
\text { programas de } \\
\text { nas bibliotecas públicas } \\
\text { para uso de deficientes } \\
\text { visuais. }\end{array}$ & $\begin{array}{l}\text { Dispõe que as bibliotecas públicas, nos } \\
\text { municípios com mais de cinqüenta mil } \\
\text { habitantes, deverão facilitar o acesso dos } \\
\text { deficientes visuais aos seus computadores, por } \\
\text { meio da implantação de programas de } \\
\text { software para esse fim. }\end{array}$ \\
\hline $\begin{array}{c}\text { Projeto de } \\
\text { Lei do } \\
\text { Senado } n^{\circ} \\
278, \text { de } 2012\end{array}$ & $17 / 07 / 2012$ & $\begin{array}{c}\text { Senador } \\
\text { Pedro Taques } \\
(\mathrm{PDT} / \mathrm{MT})\end{array}$ & $\begin{array}{l}\text { Altera a Lei } \mathrm{n}^{\circ} 10.098 \text {, } \\
\text { de } 19 \text { de dezembro de } \\
2000 \text {, para dispor sobre } \\
\text { a acessibilidade no } \\
\text { serviço de atendimento } \\
\text { ao consumidor dirigido à } \\
\text { pessoa com deficiência } \\
\text { visual e auditiva nas } \\
\text { instituições financeiras. }\end{array}$ & $\begin{array}{l}\text { Acresce os arts. 19-A e 19-B à Lei } \mathrm{n}^{\circ} \\
10.098 / 00 \text { (estabelece normas gerais e critérios } \\
\text { básicos para a promoção da acessibilidade das } \\
\text { pessoas portadoras de deficiência ou com } \\
\text { mobilidade reduzida) para prever que as } \\
\text { instituições financeiras e operadoras de cartão } \\
\text { deverão oferecer serviço de atendimento ao } \\
\text { consumidor acessíveis à pessoa com } \\
\text { deficiência visual ou auditiva, podendo para } \\
\text { tanto utilizar a internet, com atendimento } \\
\text { online, e o cadastro de pessoas de confiança } \\
\text { do usuário, para representá-lo em caso de } \\
\text { emergência nos atendimentos por meio de } \\
\text { telefones 0800. A Lei entrará em vigor cento e } \\
\text { vinte dias após sua publicação. }\end{array}$ \\
\hline $\begin{array}{l}\text { Projeto de } \\
\text { Lei da } \\
\text { Câmara no } \\
106\end{array}$ & $08 / 11 / 2012$ & $\begin{array}{l}\text { Comissão de } \\
\text { Legislação } \\
\text { Participativa }\end{array}$ & $\begin{array}{l}\text { Altera os arts. } 2^{\circ} \text { e } 17 \text { da } \\
\text { Lei } n^{\circ} 10.098, \text { de } 19 \text { de } \\
\text { dezembro de } 2000 \text {, que } \\
\text { dispõe sobre } r \text { a } \\
\text { acessibilidade } \text { das } \\
\text { pessoas portadoras de } \\
\text { deficiência ou com } \\
\text { mobilidade reduzida, } \\
\text { para acrescentar a } \\
\text { acessibilidade } \\
\text { portais públicos da } \\
\text { internet. }\end{array}$ & $\begin{array}{l}\text { Altera a Lei }{ }^{\circ} 10.098 \text {, de } 19 \text { de dezembro de } \\
2000 \text {, que dispõe sobre a acessibilidade das } \\
\text { pessoas portadoras de deficiência ou com } \\
\text { mobilidade reduzida, para acrescentar a } \\
\text { acessibilidade aos portais públicos da internet; } \\
\text { estabelece que o poder público promoverá a } \\
\text { eliminação de barreiras na comunicação e } \\
\text { estabelecerá mecanismos e alternativas } \\
\text { técnicas que tornem acessíveis os sistemas de } \\
\text { comunicação e sinalização, bem como os } \\
\text { portais públicos e de interesse público na } \\
\text { internet, às pessoas com deficiência sensorial } \\
\text { ou com dificuldade de comunicação, para } \\
\text { garantir-lhes o direito de acesso à informaça,o, } \\
\text { à comunicação, ao trabalho, à educação, ao } \\
\text { transporte, à cultura, ao esporte e ao lazer. }\end{array}$ \\
\hline $\begin{array}{c}\text { Projeto de } \\
\text { Lei da } \\
\text { Câmara }{ }^{\circ} 28\end{array}$ & 28/04/2011 & $\begin{array}{c}\text { Dep. Federal } \\
\text { Vieira Reis } \\
\text { (Sem } \\
\text { partido/RJ) }\end{array}$ & 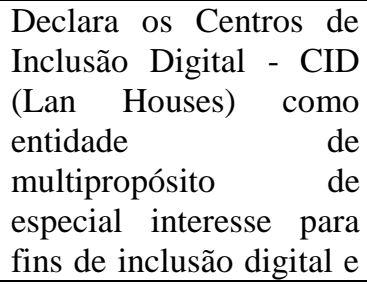 & $\begin{array}{l}\text { Declara os Centros de Inclusão Digital CID } \\
\text { (Lan Houses) como de especial interesse } \\
\text { social para universalização do acesso à rede } \\
\text { mundial de computadores para fins de garantir } \\
\text { o exercício da cidadania e, ainda, atribui-lhes a } \\
\text { característica de entidades prestadoras de } \\
\text { serviços de multipropósitos; define Centros de } \\
\text { Inclusão Digital }\end{array}$ \\
\hline
\end{tabular}

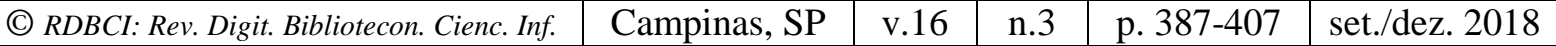




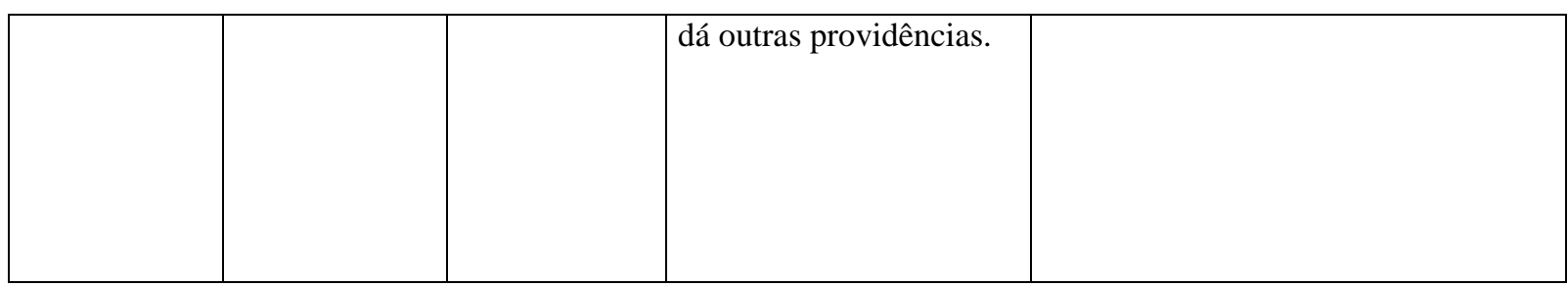

Fonte: Elaborado pelos autores (2018), baseado em informações do Senado Federal

É importante destacar que o projeto mais antigo em tramitação é datado de 2011 e o mais recente em 2014. Nota-se que após esta data, não houve a propositura de projetos relacionados à acessibilidade na web nas casas legislativas. Os projetos abordam temáticas diferentes, com propostas distintas, porém com relevância e impacto a nível nacional.

Do ponto de vista metodológico, a primeira etapa do modelo de Gordon (1999) foi elaborada a partir dos quatro projetos de lei analisados, levando em consideração os critérios de tempo de tramitação no congresso, nível de tramitação, número de tramitações do processo e última data de andamento do processo.

A segunda etapa proposta por Gordon (1999) foi elaborada com base nos mesmos critérios, ressaltando que a probabilidade inicial deve ser estimada por meio da análise de ocorrência no curto prazo, ou seja, a possibilidade do projeto de lei ser aprovado em 2018. Ademais, a probabilidade é estimada forma separada, assumindo que os outros eventos não ocorram.

Por fim, a terceira e última etapa levou em consideração as relações de causalidade entre os eventos, ou seja, se um evento " $x$ " acontece, qual a nova probabilidade de ocorrência do evento " $y$ ". Deste modo, para calcular a matriz de probabilidades condicionais utilizou-se de cálculos matemáticos de estimação de probabilidade com auxílio do software Microsoft Excel. A estimação ocorreu levando em consideração, se o evento "x" acontece, o impacto sobre o evento "y" será: "nenhum impacto", "baixo impacto", "médio impacto" e "alto impacto". Estas relações de impacto entre eventos são fundamentais para elaboração da matriz analisada na próxima seção.

\section{ELABORAÇÃO dOS CENÁRIOS}

A projeção foi feita a partir da metodologia proposta por Gordon (1999), respeitando as três etapas do modelo. A etapa (um): definição dos eventos do estudo foi realizada com base nos quatro projetos de lei detalhados nos Quadros 6 e 7, a saber: (a) implantação de programas de software nas bibliotecas públicas para uso de deficientes visuais; (b) instituição do SAC dirigido à pessoa com deficiência visual e auditiva nas instituições financeiras; (c) promoção da acessibilidade aos portais públicos na web; e (d) desenvolvimento de Centros de Inclusão Digital (CID). O quadro 7 apresenta mais informações sobre os PLS e PLC. 
Quadro 7. Informações sobre os projetos de Lei sobre acessibilidade na web

\begin{tabular}{|c|c|c|c|c|}
\hline Projeto de Lei & $\begin{array}{c}\text { Tempo de } \\
\text { tramitação no } \\
\text { congresso }\end{array}$ & Tramitação & $\begin{array}{c}\mathrm{N}^{\mathbf{0}} \text { de } \\
\text { tramitações } \\
\text { do processo }\end{array}$ & $\begin{array}{l}\text { Última data de } \\
\text { andamento do } \\
\text { processo }\end{array}$ \\
\hline $\begin{array}{l}\text { Projeto de Lei do } \\
\text { Senado } n^{\circ} 138, \text { de } \\
2014\end{array}$ & 3 anos e 5 meses & $\begin{array}{l}\text { Projeto está na Comissão } \\
\text { de Direitos Humanos e } \\
\text { Legislação Participativa } \\
\text { (Matéria com a relatoria) }\end{array}$ & 20 tramitações & $11 / 05 / 2017$ \\
\hline $\begin{array}{l}\text { Projeto de Lei do } \\
\text { Senado } n^{\circ} 278, \text { de } \\
2012\end{array}$ & $\begin{array}{c}5 \text { anos e seis } \\
\text { meses }\end{array}$ & $\begin{array}{l}\text { Projeto está na Comissão } \\
\text { de Constituição, Justiça e } \\
\text { Cidadania (Matéria com a } \\
\text { relatoria) }\end{array}$ & 44 tramitações & $19 / 06 / 2015$ \\
\hline $\begin{array}{l}\text { Projeto de Lei da } \\
\text { Câmara } n^{\circ} 106, \text { de } \\
2012\end{array}$ & 5 anos e 2 meses & $\begin{array}{l}\text { Comissão de Constituição, } \\
\text { Justiça e Cidadania } \\
\text { (Aguardando designação } \\
\text { do Relator) }\end{array}$ & 35 tramitações & 20/08/2015 \\
\hline $\begin{array}{l}\text { Projeto de Lei da } \\
\text { Câmara }{ }^{\circ} 28, \text { de } \\
2011\end{array}$ & 6 anos e 9 meses & $\begin{array}{l}\text { Pronto para deliberação do } \\
\text { Plenário do Senado } \\
\text { Federal (Aguardando } \\
\text { inclusão em Ordem do dia) }\end{array}$ & 46 tramitações & 28/08/2017 \\
\hline
\end{tabular}

Fonte: Elaborado pelos autores (2018), baseado em informações do Senado Federal

A partir do levantamento das informações demonstradas no Quadro 7, foi possível determinar a probabilidade inicial de ocorrência de cada evento. Para embasar a probabilidade inicial, etapa “dois" do Modelo de Gordon (1999), foi necessário compreender o tempo de tramitação de cada projeto, bem como em que nível se encontra, além do número de tramitação do processo e sua última data de andamento. O evento "um" obteve o índice de probabilidade inicial para 2018 de 20\%, ou seja, 0,2. O evento "dois" e "três" receberam 10\% de probabilidade e, por fim, o evento "quatro" é o mais provável de ocorrer, conforme apresenta a Tabela 1 .

Tabela1. Probabilidade inicial de ocorrência dos eventos em 2018

\begin{tabular}{l|c}
\hline \multicolumn{1}{c|}{ Evento } & $\begin{array}{c}\text { Probabilidade } \\
\text { inicial para 2018 }\end{array}$ \\
\hline $\begin{array}{l}\text { 1. Implantação de programas de software nas bibliotecas públicas para uso } \\
\text { de deficientes visuais. }\end{array}$ & $\mathbf{0 , 2}$ \\
\hline $\begin{array}{l}\text { 2. Instituição do SAC dirigido à pessoa com deficiência visual e auditiva } \\
\text { nas instituições financeiras. }\end{array}$ & $\mathbf{0 , 1}$ \\
\hline 3. Promoção da acessibilidade aos portais públicos na web. & $\mathbf{0 , 1}$ \\
\hline 4. Desenvolvimento de Centros de Inclusão Digital (CID). & $\mathbf{0 , 4}$ \\
\hline
\end{tabular}

Fonte: Elaborado pelos autores (2018)

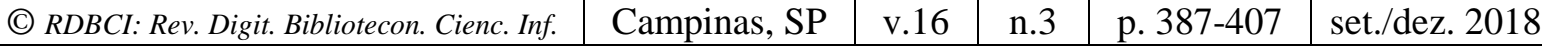


O evento "um" faz referência à implantação de programas de software nas bibliotecas para uso de deficientes visuais e baseia-se no Projeto de Lei do Senado no 138 , de 2014. A probabilidade inicial de $20 \%$ leva em consideração que o projeto está com relator definido, passou por 20 tramitações e sua última ocorreu em 2017. Os eventos "dois" e "três" possuem $10 \%$ de probabilidade inicial justificada pela sua última tramitação ocorrida em 2015 . O evento "quatro", desenvolvimento de Centros de Inclusão Digital (CID), possui a maior probabilidade inicial, obtendo $40 \%$ de chances de ser aprovado em 2018. O índice baseia-se na premissa que o projeto já passou por todos os processos de tramitação, está em discussão desde 2011 e encontra-se pronto para deliberação do Plenário do Senado Federal, aguardando apenas a inclusão na Ordem do dia.

A etapa "três" busca estimar as probabilidades condicionais por meio de uma matriz de impacto cruzado. Foi elaborada levando em consideração a seguinte premissa: se um evento "x" ocorrer, qual a nova probabilidade de ocorrência do evento "y"? Além disso, foi necessário o uso de fórmulas matemáticas de probabilidade para realização dos cálculos. As fórmulas foram adaptadas ao Microsoft Excel 2013 e aplicadas com o objetivo de elaborar a matriz, considerando os critérios apresentados nos procedimentos metodológicos. A Tabela 2 apresenta a matriz de impacto cruzado elaborada com as probabilidades condicionais.

Tabela 2. Matriz de probabilidades condicionais

\begin{tabular}{l|c|c|c|c|c}
\hline \multicolumn{1}{c|}{ Se este evento ocorrer: } & $\begin{array}{c}\text { Probabilidade } \\
\text { inicial para 2018 }\end{array}$ & $\begin{array}{c}\text { Evento } \\
\text { um }\end{array}$ & $\begin{array}{c}\text { Evento } \\
\text { dois }\end{array}$ & $\begin{array}{c}\text { Evento } \\
\text { três }\end{array}$ & $\begin{array}{c}\text { Evento } \\
\text { quatro }\end{array}$ \\
\hline $\begin{array}{l}\text { 1. Implantação de programas de } \\
\text { software nas bibliotecas públicas para } \\
\text { uso de deficientes visuais. }\end{array}$ & 0,2 & - & 0,1 & 0,25 & 0,5 \\
\hline $\begin{array}{l}\text { 2. Instituição do SAC dirigido à pessoa } \\
\text { com deficiência visual e auditiva nas } \\
\text { instituições financeiras. }\end{array}$ & 0,1 & 0,2 & - & 0,1 & 0,4 \\
\hline $\begin{array}{l}\text { 3. Promoção da acessibilidade aos } \\
\text { portais públicos na web. }\end{array}$ & 0,1 & 0,3 & 0,1 & - & 0,5 \\
\hline $\begin{array}{l}\text { 4. Desenvolvimento de Centros de } \\
\text { Inclusão Digital (CID). }\end{array}$ & 0,4 & 0,4 & 0,1 & 0,3 & - \\
\hline
\end{tabular}

Fonte: Elaborado pelos autores (2018)

Ao analisar a Tabela 2 é possível compreender que se o evento 1 ocorrer não gerará impacto no evento "dois", porém aumentará a probabilidade de ocorrência do evento "três" e "quatro", respectivamente. Sendo assim, caso ocorra a implantação de programas de software em bibliotecas públicas, aumentará a possibilidade de aprovação dos projetos de lei que visão a promoção da acessibilidade nos portais públicos em $15 \%$ e implantação de centros de inclusão digital em $10 \%$. 
Aparentemente, o evento "dois" não gerará interferência nos demais eventos, pois não possui relação direta e trata especificamente de um nicho específico de atuação e visa melhorias nas instituições financeiras. Por outro lado, caso ocorra o evento "três", aumentará a probabilidade do evento "um" e do evento "quatro" ocorrer em 10\%. Por fim, o que possui a maior relação com os demais é o desenvolvimento de Centros de Inclusão Digital (CID), correspondente ao evento "quatro". Isso significa que caso ocorra, aumentará a possibilidade de ocorrência dos demais. Neste caso, a ocorrência do evento "quatro" aumenta a chance de ocorrência do evento "um" e "três" em $20 \%$.

A partir dos dados elaborados por meio do método de Gordon (1999) foi possível desenvolver os cenários prospectivos com base nos projetos de lei para acessibilidade na web no Brasil, a saber:

a) Cenário pessimista: não ocorrência dos eventos previstos. $O$ arquivamento dos projetos de lei que estão em tramitação podem ocasionar este cenário. Devido à instabilidade política, prioridades distintas de interesses sociais defendidos pelos parlamentares e outros fatores podem conduzir à possibilidade de que nenhum dos projetos que estão em tramitação possam ser aprovados.

b) Cenário realista: o cenário mais provável é que ocorra o evento 4, ou seja, o desenvolvimento de Centros de Inclusão Digital (CID) por meio da aprovação da Lei da Câmara $\mathrm{n}^{\circ} 28$, de 2011. O projeto encontra-se pronto para deliberação dos parlamentares e possui chances de apreciação em curto e médio prazo. A partir da sua aprovação, aumenta a possibilidade de ocorrência da implantação de programas de software nas bibliotecas públicas para uso de deficientes visuais, como também a promoção da acessibilidade aos portais públicos na web. É provável que os projetos que abordam estes aspectos tramitem com maior agilidade.

c) Cenário otimista: a possibilidade da ocorrência do evento 4 devido à aprovação do projeto de Lei em curto prazo pode impulsionar a aprovação em médio prazo dos projetos de Lei que fazem referência aos eventos "um" e "três". Sendo assim, numa visão otimista, poderá ocorrer o desenvolvimento de Centros de Inclusão Digital (CID) no curto prazo e a implantação de programas de software nas bibliotecas públicas para uso de deficientes visuais, como também da Promoção da acessibilidade aos portais públicos na web no médio prazo. O evento "dois", por não possuir relação direta com os demais eventos, pode, em uma visão otimista, tramitar e ser aprovado no longo prazo.

Os cenários projetados levaram em consideração os argumentos de Wright, Silva e Spers (2010) quando descrevem a importância de observar as forças que atuam sobre cada variável. É fundamental perceber as relações que os eventos possuem entre si e de que forma podem ser influenciados por diversos fatores. Neste caso específico, a análise foi baseada principalmente nas informações sobre o processo de tramitação dos projetos de Lei.

\begin{tabular}{l|l|l|l|l|l} 
(C) RDBCI: Rev. Digit. Bibliotecon. Cienc. Inf. & Campinas, SP & v.16 & n.3 & p. $387-407$ & set./dez. 2018 \\
\hline
\end{tabular}


Sabe-se, porém, que existem diversos interesses no cenário político que podem interferir direta ou indiretamente na aprovação ou não apreciação dos projetos de Lei. Godet e Durance (2011) comentam que a projeção de cenários pode auxiliar na previsão de uma situação de origem para uma situação futura, porém, compreende-se que o objeto estudado possui fatores limitantes que só serão observados à medida que ocorrerem, como por exemplo, pressão popular, alianças partidárias, pautas de interesse político/social, entre outros.

\section{CONSIDERAÇõES FINAIS}

O presente artigo apresentou cenários prospectivos para acessibilidade na web com base nos projetos de lei do Senado Federal e da Câmara dos Deputados. Para tanto, foi necessário realizar um levantamento sobre os projetos de Lei que estão em tramitação e avaliar aspectos como ementa, explicação detalhada da ementa, número de tramitações, relatoria, data da última tramitação, tempo de tramitação e autoria dos projetos. Estes elementos foram avaliados para elaboração dos cenários seguindo as etapas propostas por Gordon (1999).

Além disso, realizou-se um levantamento preliminar sobre as principais leis que estão em tramitação no país, bem como um panorama sobre as Convenções internacionais e Resoluções da ONU. É importante salientar que a última lei sobre acessibilidade na web foi aprovada em 2015 no Brasil, a Lei Brasileira de Inclusão da Pessoa com Deficiência - LBI Lei $\mathrm{n}^{\circ} 13.146$.

Em relação aos cenários propostos, foi possível identificar a existência de três possibilidades: pessimista, realista e otimista. Numa visão pessimista é provável que nenhum projeto de lei seja sancionado. Por outro lado, o cenário realista identificou a possibilidade de aprovação do projeto de lei que busca o Desenvolvimento de Centros de Inclusão Digital (CID). Caso ocorra este evento, é provável que os projetos que fazem referência implantação de programas de software nas bibliotecas públicas para uso de deficientes visuais, como também o projeto que prever a promoção da acessibilidade aos portais públicos na web possam ser discutidos com maior afinco pelo Senado Federal. No cenário otimista, é possível que haja a aprovação destas últimas três leis. A incógnita é a aprovação da lei que se refere à instituição do SAC dirigido à pessoa com deficiência visual e auditiva nas instituições financeiras.

Ressalta-se que os cenários apresentados resumem-se apenas as observações e análises feitas com base nos quatro projetos de lei que estão em tramitação sobre algum aspecto da acessibilidade na web. Neste sentido, é provável que a elaboração de cenários feita por um método diferente do adotado pode gerar resultados divergentes. Além disso, é importante mencionar que fatores limitantes e peculiares à política no Brasil não foram levados em 
consideração. De toda forma, é possível, por meio dos cenários propostos, obter um panorama sobre o que pode ocorrer no futuro em relação aos projetos de lei avaliados.

\section{REFERÊNCIAS}

ALEXANDER, D. How accessible are Australian university Web sites? In: AUSTRALIAN WORLD WIDE WEB CONFERENCE, 9, 2003, Austrália. Proceedings of ausWeb03. Disponível em: 〈http://ausweb.scu.edu.au/aw03/papers/alexander3/paper.html>. Acesso em: 10 jan. 2018.

BRASIL. Decreto legislativo $\mathbf{n}^{\mathbf{0}} \mathbf{1 8 6}$, de 2008. Aprova o texto da Convenção sobre os Direitos das Pessoas com Deficiência. 2008. Disponível em: <http://www.planalto.gov.br/ccivil_03/constituicao/congresso/DLG/DLG-186-2008.htm>. Acesso em: 16 jan. 2018.

BRASIL. Decreto no 3.298 de 20 de dezembro de 1999. Dispõe sobre a Política Nacional para a Integração da Pessoa Portadora de Deficiência, consolida as normas de proteção, e dá outras providências. 1999. Disponível em:

<http://www.planalto.gov.br/ccivil_03/decreto/d3298.htm>. Acesso em: 04 jan. 2018.

BRASIL. Decreto $N^{0} 5.296$ de 2 de Dezembro de 2004. Dá prioridade de atendimento às pessoas que especifica e estabelece normas gerais e critérios básicos para a promoção da acessibilidade das pessoas portadoras de deficiência ou com mobilidade reduzida. 2004.

Disponível em: 〈http://www.planalto.gov.br/ccivil 03/ ato2004-2006/2004/decreto/d5296.htm>. Acesso em: 04 jan. 2018.

BRASIL. Legislação brasileira sobre pessoas portadoras de deficiência. 5. ed. Brasília: Câmara dos Deputados, Edições Câmara, 2009a.

BRASIL. Lei N. 10.098 de 19 de dezembro de 2000. Estabelece normas gerais e critérios básicos para a promoção da acessibilidade das pessoas portadoras de deficiência ou com mobilidade reduzida, e dá outras providências. 2000. Disponível em:

<http://www.planalto.gov.br/ccivil_03/leis/110098.htm>. Acesso em: 06 jan. 2018.

BRASIL. Lei $\mathbf{N}^{\mathbf{0}} \mathbf{7 . 8 5 3}$, de 24 de outubro de 1989. Dispõe sobre o apoio às pessoas portadoras de deficiência, sua integração social, sobre a Coordenadoria Nacional para Integração da Pessoa Portadora de Deficiência. 1989. Disponível em:

<http://www.planalto.gov.br/ccivil_03/leis/17853.htm>. Acesso em: 04 jan. 2018.

BRASIL. Portaria N 3.128, de 24 de Dezembro de 2008. Define que as Redes Estaduais de Atenção à Pessoa com Deficiência Visual sejam compostas por ações na atenção básica e Serviços de Reabilitação Visual. 2008. Disponível em: <http://bvsms.saude.gov.br/bvs/saudelegis/gm/2008/prt3128_24_12_2008.html >. Acesso em: 06 jan. 2018. 
BRASIL. Decreto $\mathbf{N}^{\circ}$ 6.949, de 25 de agosto de 2009. Promulga a Convenção Internacional sobre os Direitos das Pessoas com Deficiência e seu Protocolo Facultativo, assinados em Nova York, em 30 de março de 2007. 2009b. Disponível em:

<http://www.planalto.gov.br/ccivil 03/ ato2007-2010/2009/decreto/d6949.htm>. Acesso em: 08 fev. 2018

BRASIL. Secretaria de Direitos Humanos da Presidência da República. Secretaria Nacional de Promoção dos Direitos da Pessoa com Deficiência. Coordenação Geral do Sistema de Informações sobre a Pessoa com Deficiência. Cartilha do Censo 2010: pessoas com deficiência. Brasília: SDR-PR/SNPD, 2012.

BRASIL. Lei no 13.146, de 06 de julho de 2015. Institui a Lei Brasileira de Inclusão da Pessoa com Deficiência (Estatuto da Pessoa com Deficiência). 2015. Disponível em: <http://www.planalto.gov.br/ccivil_03/_Ato2015-2018/2015/Lei/L13146.htm>. Acesso em: 12 jan. 2018.

BRASIL. Constituição (1988). Constituição da República Federativa do Brasil. Brasília, DF: Senado Federal: Centro Gráfico, 1988. Disponível em:

<http://www.planalto.gov.br/ccivil 03/constituicao/constituicaocompilado.htm>. Acesso em: 12 jan. 2018.

CÂMARA DOS DEPUTADOS. Documentos legislativos: projetos de lei. 2018. Disponível em: <http://www2.camara.leg.br/a-camara/conheca/processolegislativo/elaboracaolegislativa/documentos/projeto-de-lei $>$. Acesso em: 19 jul. 2018.

COUSIN, C. Acessibilidade em ambientes informacionais digitais. Tese (Doutorado em Ciência da Informação) - Faculdade de Filosofia e Ciências, Universidade Estadual Paulista, 2010.

FADERS. Fundação de Articulação e Desenvolvimento de Políticas Públicas para Pessoas com Deficiência e com Altas Habilidades no Rio Grande do Sul. Convenção Sobre Reabilitação Profissional e Emprego de Pessoas Deficientes. 2018. Disponível em: $<$ http://www.faders.rs.gov.br/legislacao/6/46>. Acesso em: 10 jan. 2018.

GIL, A. Métodos e técnicas de pesquisa social. 6. ed. São Paulo: Atlas, 2008.

GODET, M.; DURANCE, P. Prospectiva estratégica: para as empresas e os territórios. UNESCO. Ed. DUNOD. Versão portuguesa pela IEESF. Direção prof. Júlio G. Dias. 2011. $180 \mathrm{p}$.

GORDON, T. Método de impacto cruzado. 1999. Disponível em: <http://saludpublicavirtual.udea.edu.co/cvsp/politicaspublicas/gordon_impacto_cruzado.pdf>. Acesso em: 12 jan. 2018.

GUIMARÃES, Í. Acessibilidade em websites de comércio eletrônico: avaliação através da interação com usuários cegos. Dissertação (Mestrado) - Universidade Federal da Paraíba, 2016. 
HENRY, S. L. Education and Outreach Working Group (EOWG). Introduction to Web Accessibility. W3C/WAI - World Wide Web Consortium / Web Accessibility Initiative. 2005. Disponível em: 〈http://www.w3.org/WAI/intro/accessibility.php〉. Acesso em: 12 jan. 2018.

KAMIMURA, A. O emprego da matriz de impactos cruzados no esboço de cenários futuros. Revista Brasileira de Energia, vol. 3, n.2, 1994.

LAZZARIN, F. De olho no OPAC da biblioteca universitária: avaliação sobre eacessibilidade e arquitetura da informação para Web com a interação de usuários cegos. Dissertação (Mestrado) - Universidade Federal da Paraíba, 2014.

LIRA, S. L.; ARAÚJO, W. J.; DUARTE, E. N. Cenários prospectivos para implantação de Comunidades de prática em unidades de Contabilidade em universidades públicas. Perspectivas em Gestão \& Conhecimento, João Pessoa, v. 7, n. 1, p. 170-190, jan./jun. 2017.

MINAYO, M. Trabalho de campo, contexto de observação, interação e descoberta.

In: . (Org.). Pesquisa Social: teoria, método e criatividade. 28. ed. Petrópolis: Vozes, 2009.

MORITZ, G. O.; PEREIRA, M. F. Planejamento de cenários: a evolução do pensamento prospectivo. Revista de Ciências da Administração, v.7, n.13, jan./jul. 2005.

NEVES, E.; DOMINGUES, C. (Org.). Manual de metodologia da pesquisa científica. Rio de Janeiro: EB/CEP, 2007.

SANTOS, J. M. L. Livro Digital: estudo de cenários do setor editorial nacional. Dissertação (Mestrado) - Universidade Federal da Paraíba, 2017.

SANTOS, M. O. G. Texto de apoio sobre o método de cenários. 2011. Disponível em: <http://home.uevora.pt/ mosantos/download/Cenars TextoApoio_25Jul2011.pdf > . Acesso em: 27 jan. 2018.

SANTOS, M. M.; Et al. Prospecção de tecnologias de futuro: métodos, técnicas e abordagens. Pac. Estrat., Brasília, n.19, p. 1-334, dez. 2004.

SENADO FEDERAL. Projeto de Lei (PL). 2018. Disponível em: <https://www12.senado.leg.br/orcamento/glossario/projeto-de-lei-pl>. Acesso em: 19 jul. 2018.

ONU. Organização das Nações Unidas. Declaração Universal dos direitos humanos. 1948. Disponível em: 〈http://unesdoc.unesco.org/images/0013/001394/139423por.pdf〉. Acesso em: 09 jan. 2018.

WRIGHT, J. T. C.; SILVA, A. T. B.; SPERS, R. G. Prospecção de cenários: uma abordagem plural para o futuro do Brasil em 2020. Revista Ibero-Americana de Estratégia - RIAE, São Paulo, v. 9, n. 1, p. 56-76, jan./abr. 2010. 


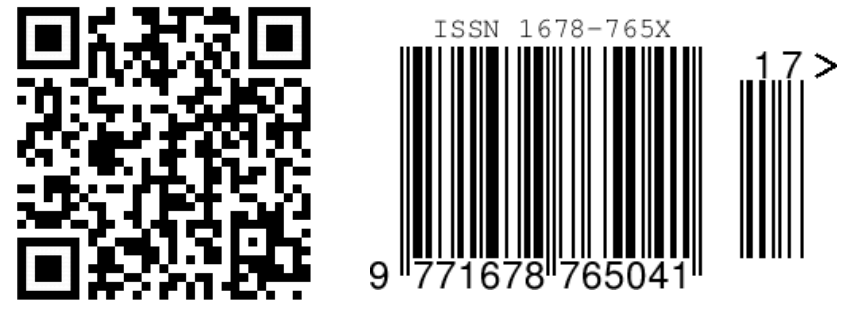

